\title{
O fundamento do conhecimento em L'être et le néant
}

\author{
The foundation of knowledge in L'être et le néant
}

Gustavo Fujiwara ${ }^{2}$

\begin{abstract}
Resumo: Pretendemos analisar neste artigo o fundamento ontofenomenológico do conhecimento em L'être et le néant (1943). Como veremos, o conhecimento será concebido a partir de uma negação de tipo interna definida como relação ontológica fundamental entre ser-para-si e ser-em-si. Todavia, caso almejemos compreender o estatuto profundo de uma tal relação, teremos que escrutinar as definições sartreanas de ser do fenômeno e fenômeno de ser, ser transfenomenal, ser-em-si, ser-para-si e estrutura reflexo-refletidora do cogito. Recuperando tais definições, mostraremos que a identidade do ser do para-si e do conhecimento, antes de sinalizar que o conhecimento seja a medida do ser, desponta de um registro ontofenomenológico no qual o para-si, enquanto nada de ser, anuncia a si mesmo a partir do em-si.
\end{abstract}

Palavras-chave: Conhecimento; Ontologia Fenomenológica; Negação; Consciência.

\begin{abstract}
We intend to analyze in this article the ontophenomenological basis of knowledge in L'être et le néant (1943). As we will see, the knowledge will be defined from an internal negation defined as the fundamental ontological relation between being-for-itself and being-in-itself. However, if we want to understand this relationship, we will have to scrutinize Sartre's definitions of being of the phenomenon and the phenomenon of being, transphenomenal being, being-in-itself, being-for-itself, and reflexive-reflective structure of the cogito. Recovering this definitions, we will show that the identity of being-for-itself and knowledge, before signaling that knowledge is the measure of being, emerges from an ontophenomenological record in which the for-itself, while nothingness, announces itself from the in-itself.
\end{abstract}

Keywords: Knowledge; Phenomenological Ontology; Negation; Consciousness.

\footnotetext{
${ }^{1} \mathrm{O}$ presente artigo deriva de uma pesquisa mais extensa de doutorado financiada pela Fapesp, processo número: 2014-09973-4.

${ }^{2}$ Doutor em Filosofia pela Universidade Federal de São Paulo. Guarulhos, São Paulo, Brasil. Pós-doutorando em Filosofia, UFSCar, sob a supervisão teórica do professor Dr. Luiz Damon Santos Moutinho.
} 


\section{I - Ser do fenômeno e fenômeno de ser}

L'être et le néant ${ }^{3}$, após investigar e definir o tipo de ser do para-si e o tipo de ser do em-si, buscará, na segunda parte, capítulo três, seção I, "La connaissance comme type de relation entre le pour-soi et l'en-soi", responder "como e por qual razão o para-si tem de ser, em seu ser, conhecimento do em-si (...)” (SARTRE, 2010a, p. 208). Porquanto o serem-si, na Introdução da referida obra, tenha sido definido como uma plena identidade inerte a si mesmo, não poderíamos buscar o fundamento do conhecimento neste ser que se basta a si mesmo; logo, "é no para-si que devemos buscar a chave dessa relação ao ser que nomeamos, por exemplo, conhecimento", pois, continua o filósofo, "o para-si é responsável, em seu ser, por sua relação com o em-si ou, se se prefere, ele se produz originalmente a partir do fundamento de uma relação ao em-si” (SARTRE, 2010a, p. 208). Contudo, caso queiramos compreender a definição sartreana do conhecimento, será preciso que revisitemos alguns momentos chave da magnum opus antes de nos debruçarmos efetivamente na questão deste artigo, isto é, o fundamento (ontofenomenológico) do conhecimento; senão vejamos.

Na seção II, "Le phénomène d'être et l'être du phénomène", da Introdução de $E N$, Sartre visa o entrecruzamento da fenomenologia com a ontologia buscando superar o idealismo e o realismo. Neste sentido, o filósofo deverá colocar o problema do ser do fenômeno e do fenômeno de ser, afinal, "se a essência da aparição é um 'aparecer' que não se opõe mais a nenhum ser, há um problema legítimo do ser desse aparecer" (SARTRE, 2010a, p. 14). Em linhas gerais, esta questão aparece contra, de um lado, o dualismo do fundamento substancial e, de outro lado, contra o dualismo da aparição do aparecer: "dizer que a aparição implique um ser que não aparece é o mesmo que dizer que a aparição exige uma passagem ao não aparente, ao não fenomenal, à condição do fenômeno" (MOUTINHO, 2006, p. 91). Pode-se dizer que o "há" da presença assinala eo ipso uma passagem do ser à fenomenalidade (sem que, todavia, este ser seja ultrapassado) por meio do surgimento da consciência ou para-si ${ }^{4}$. Há, se

\footnotetext{
${ }^{3}$ Doravante abreviado EN.

4 "Apreendida em sua pureza, a consciência é uma condição de aparição de todo fenômeno (...). Sua lei de existência é a de esgotar-se no aparecer e de não existir de outra maneira a não ser como consciência de existir" (MOUILLE, 200o, p. 31). Assim, diremos que o ser da consciência é consciência de ser. Sobremaneira, "cada uma de nossas
} 
quisermos, uma dupla necessidade ontofenomenológica (de um lado o ser, do outro a consciência) para que a presença se realize. Desta lida, constatase, de acordo com Sartre, que a aparição, antes de ser sustentada por um outro existente, tem um ser próprio do qual podemos falar e possuímos alguma compreensão. Entrementes, devemos fazer da pergunta do filósofo a nossa: "o fenômeno de ser, assim alcançado, é idêntico ao ser do fenômeno, ou seja, o ser que a mim se desvela, que me aparece, é da mesma natureza do ser dos existentes que me aparecem?” (SARTRE, 2010a, p. 14). O fenômeno de ser é, tal e qual, o ser do fenômeno? Tanto Husserl (redução eidética) como Heidegger (realidade-humana ônticoontológica, isto é, ela pode sempre ultrapassar o fenômeno em direção a seu ser) não atingem o ser do fenômeno, pois“o ser dos fenômenos não se reduz ao fenômeno de ser" (SARTRE, 2010a, p. 15). Ainda que possamos distinguir, em um X qualquer, certas qualidades como cor ou odor e, a partir delas, fixar uma essência que não está no X, mas é o sentido deste $\mathrm{X}, \mathrm{o}$ "ser não é nem uma qualidade do objeto apreensível entre outras, nem um sentido do objeto. O objeto não remete ao ser como se fosse uma significação" (SARTRE, 2010a, p. 15).

Todo o imbróglio sartreano está no fato de que o ser "é para desvelar e não ser desvelado", ou seja, o ser do fenômeno, ainda que não se solucione em um fenômeno de ser, somente pode ser "descrito" se, e somente se, consultarmos ofenômeno de ser que, por seu turno, entregase fenomenologicamente, à consciência. Porém, se o ser "é-para-desvelar" e não o contrário, ou seja, "ser desvelado", tal fato indica (ontologicamente) que ele subjaz como fundamento do desvelamento; daí que "a relação exata que une o fenômeno de ser ao ser do fenômeno deve ser estabelecida antes de tudo" (SARTRE, 2010a, p. 15). Destarte, este fenômeno de ser, enquanto fenômeno, exige um fundamento outro que não seja tributário da consciência (sob o risco de esbarrarmos no idealismo), logo, exige-se um fundamento que seja transfenomenal (fundamento da manifestação do fenômeno enquanto ser do fenômeno).

Desta exigência, Sartre asseverará que o ser do fenômeno é coextensivo ao fenômeno e que ele não poderá se limitar à condição fenomênica, ou seja, ele deverá escapar da condição de algo que somente 
existiria caso fosse revelado por uma consciência, pois "o fenômeno remete ao ser, é um apelo de ser; neste sentido, ele implica uma ontologia" (MOUTINHO, 2006, p. 91). Enquanto fenômeno, ele exige um fundamento que seja transfenomenal. Se o ser (sua transfenomenalidade) é condição ontológica do desvelamento do fenômeno, por outro, a consciência é condição fenomenológica do "há" deste fenômeno5: "'há' ser porque o para-si é tal que faz com que haja ser. O caráter de fenômeno vem ao ser pelo para-si” (SARTRE, 2010a, p. 667). A fenomenalização se realiza sob o fundo de um ser que, contudo, não pode ser, ele mesmo, a origem deste processo $^{6}$. Se se almeja não tropeçar no idealismo de Berkeley segundo o qual "esse est percipi" - ser é ser percebido -7, Sartre deve frisar que o fenômeno possui uma existência independente da consciência: ora, se o sentido desse fenômeno é dado pela consciência (fenomenologia), isso não significa, todavia, ele seja dependente da consciência, posto ser transfenomenal (ontologia), "isto é, o fenômeno não é apenas sua manifestação limitada e imediata, mas contém, em sua manifestação, um ser" (SOUZA, 2012, p. 158).

No entrecruzamento da ontologia com a fenomenologia, o filósofo francês institui uma ontologia fenomenológica que não se satisfaz com a trama fenomênica (a de Husserl, sob a letra de Sartre) segundo a qual o percipi (o percebido, o fenômeno) remeteria a um ser que escaparia às leis da aparição com a condição de que esse ser transfenomenal fosse o ser do sujeito (percipiens ou consciência); trama que faria com que caíssemos, mais uma vez, no esse est percipi (assimilação do ser da aparição a seu aparecer), reino do idealismo ${ }^{8}$. Para Sartre, ao contrário do pensamento husserliano, a presença implica um ser que não aparece, "aquilo que assegura a transcendência do fenômeno não pode aparecer; é esse o núcleo do argumento de Sartre" (MOUTINHO, 2006, p. 90).

Embora o ser transfenomenal não apareça, reforcemos, ele é coextensivo ao fenômeno de ser: o fenômeno exige a transfenomenalidade

\footnotetext{
5 "Os dois modos de ser que estruturam a fenomenalidade estão, contudo, em uma relação de assimetria, pois somente a consciência é incumbida da relação de constituição e de desvelamento que converte o ser em mundo" (MOUILLE, 2000, p. 31).

${ }^{6}$ Afinal o ser-em-si, enquanto plenitude de ser, nada pode fundar.

7 "E é bem, com efeito, o que fará Husserl, quando, após ter efetuado a redução fenomenológica, tratará o noema como irreal e declarará que seu 'esse' é um 'percipi”' (SARTRE, 2010a, p. 16).

8 "Se Husserl reduz corretamente o objeto à série de suas aparições ou manifestações ou maneiras de ser, em contrapartida, com o fenomenismo, ele ignora o ser do fenômeno” (CABESTAN, 2004, p. 323).
} 
do ser, o não fenomenal como sua condição de existência. Todavia, se o fenômeno exige o ser, o ser, por sua vez, não se dá sem o fenômeno: daí que eles sejam dois termos separados de direito, mas, de fato, inseparáveis. Ora, se através da consciência somos os "detectores" do ser, ou seja, apreendemos, a partir dele, o fenômeno - o X qualquer -, por outro, não somos os produtores deste ser: "essa paisagem, se dela nos desviarmos, se estagnará, longe dos olhos, em sua permanência obscura (...) não há ninguém suficientemente louco para acreditar que ela desaparecerá" (SARTRE, 1980, p. 50). Finalmente, chegamos ao ponto nevrálgico da ontologia fenomenológica de Sartre: a relação dicotômica, dual ${ }^{9}$, entre fenômeno de ser (fenomenologia) e ser do fenômeno (ontologia), relação que nos conduz a um ser transfenomenal (ontologia fenomenológica), fundamento da aparição do fenômeno pelo qual poderemos apreender o sentido do ser. Ademais, como sublinha Sartre em sua conferência para a Société française de philosophie: "o ser é algo que não posso apreender em seu ser, salvo como fenômeno a partir do objeto que é apresentado. O ser é o que faz com que o objeto apareça" (SARTRE, 2003, p. 145); porém, o objeto somente pode aparecer se, do outro lado, houver uma consciência que o apreenda.

Doravante, se se almeja uma maior compreensão deste do ser do fenômeno e do fenômeno de ser, é preciso que nos debrucemos em outro ser tratado na seção III, "Le cogito préréflexif et l'être du percipere", da Introdução: a consciência. Urge, portanto, deslindar o ser da consciência em oposição ao ser do fenômeno sem, todavia, reduzi-los à reflexão (ou conhecimento). Em linhas gerais, o esforço do Autor será o de instituir uma consciência "que não possui a abstração de uma instância gnosiológica, mas a espessura de uma prova (de) si indexada através da experiência do mundo" (DE COOREBYTER, 2000, p. 333). Nas tramas teóricas da obra em comento, esta terceira seção tem sua razão de ser uma vez demonstrada a necessidade da transfenomenalidade do ser, necessidade posta pelo fenômeno de ser. Nesta perspectiva, a consciência entra em cena como a dimensão de ser transfenomenal do sujeito, dimensão de ser que devemos elucidar.

De fato, Husserl, sob a letra sartreana, está certo ao afirmar que a consciência é o ser cognoscente enquanto é e não enquanto é conhecido:

${ }^{9}$ Dualidade que, contudo, encerra-se em uma unidade indissolúvel. 
afirmação que, de uma vez por todas, faz com que abandonemos o primado do conhecimento e olhemos a consciência para além de um conhecimento voltado sobre si. Além disso, se a consciência é um "pleno de existência”, tal característica (ontológica) vem corroborar com a ideia de um absoluto de existência que, antes de engendrar um saber (de) si, assinala uma experiência (situação) que não é conhecimento, mas no qual todo conhecimento será relativo: "sendo conhecimento desta experiência (em um retorno sobre si) ou por esta experiência (pois o conhecimento é modalidade particular de um ser-no-mundo consciente (de) si)" (DE COOREBYTER, 2000, p. 334). A consciência põe a si mesma como o fundamento último e assegura o conhecimento de maneira não circular, ou seja, sem implicar a dualidade sujeito-objeto, e isto exatamente pelo fato de que ela é reduzida à sua dimensão existencial como consciência (de) si. Logo, Sartre se afasta da tradição filosófico-epistemológicaepistemológica que, assimilando consciência à consciência reflexiva, designa nela uma relação exclusiva de conhecimento. Ao qualificar a consciência como um absoluto, ele assevera uma experiência que não é da ordem do conhecimento e na qual o conhecimento será relativo: ela não se reduzirá a um ser conhecido, mas será, ao contrário, um modo de ser que será designado como existência; daí que esta consciência seja o ser cognoscente enquanto é (enquanto existe) ao invés de ser conhecido. Inevitavelmente, este registro da consciência diz respeito ao cogito préreflexivo amparado pela máxima "toda consciência é consciência de (...)". Mas o que isso significa? Significa que a consciência somente pode ser consciência em detrimento de um objeto transcendente que, por princípio, está fora dela. O objeto, não sendo uma representação da consciência, é um centro de opacidade transcendente que, se posto na consciência, faria dela uma substância ou uma coisa.

A fenomenologia, tal como Sartre a compreende, indica que sou consciência consciente na exata medida em que tenho consciência do objeto. Porém, esta consciência consciente de si e do objeto, "não basta, certamente, para permitir-me afirmar que esta mesa exista em si - mas bem que ela existe para mim" (SARTRE, 2010a, p. 18). Tocamos aqui, finalmente, no ponto essencial que deverá guiar toda a investigação acerca do ser da consciência: o cogito pré-reflexivo ou consciência de consciência 
(não posicional). Que o leitor, aqui, não se deixe enganar - como Alain ${ }^{10}$, por exemplo - que esta consciência de consciência desponte no primado do conhecimento à maneira da idea ideae de Espinosa como conhecimento de conhecimento. Reduzir a consciência ao conhecimento implica, inexoravelmente, introduzir nela a dualidade sujeito-objeto, dualidade típica das teorias do conhecimento clássicas. Na medida em que tomamos como ponto de partida o conhecimento, diluímos o mundo em termos de uma dualidade sujeito-objeto e, "desse modo, sempre que pretendemos conhecer esse sujeito (que conhece o objeto) somos remetidos a mais uma dualidade, já que esse sujeito torna-se agora o objeto de um terceiro sujeito, e assim sucessivamente" (RODRIGUES, 2010, p. 24). Ao contrário desta remissão ad infinitum, a consciência de consciência, consciência de si, deverá ser "relação imediata e não cognitiva de si a si” (SARTRE, 2010a, p. 19), estrutura pré-reflexiva (ou irrefletida) que dissolve a díade cognoscente-conhecido. Para que evitemos remissão ao infinito, Sartre, a partir do terreno já arado pela fenomenologia, relembra que a consciência, antes de ser reflexiva, é consciência irrefletida, consciência não-tética de si ou não posicional que desponta como primeira em relação à consciência de segundo grau.

A prioridade ontofenomenológica da consciência de primeiro grau pode ser averiguada através do seguinte exemplo: ao contar os doze cigarros que percebo em meu maço, não tenho consciência posicional de contá-los, "eu não me conheço contando", pois, "no momento onde esses cigarros se revelam a mim como doze, tenho uma consciência não-tética de minha atividade aditiva" (SARTRE, 2010a, p. 19) ${ }^{11}$; a consciência nãoreflexiva de contar, portanto, é a condição de minha atividade aditiva. Para contar, é preciso ter consciência de contar; para saber, é preciso ter consciência de saber: "Nós compreendemos agora porque a consciência primeira de consciência não é posicional: identifica-se com a consciência da qual é consciência” (SARTRE, 2010a, p. 20). Assim, de uma só vez, esta

\footnotetext{
10 “Alain, tendo exprimido esta evidência: 'Saber, é ter consciência de saber ', a traduz nestes termos: 'Saber, é saber que se sabe'. Assim, teríamos definido a reflexão ou consciência posicional da consciência ou, melhor ainda, conhecimento da consciência (...). Não nos parece que possamos aceitar esta interpretação da consciência de consciência” (SARTRE, 2010a, p. 18).

${ }^{11}$ A prova desta consciência irrefletida, aliás, “(...) é que as crianças que são capazes de realizar uma adição espontaneamente, não podem, em seguida, explicar como chegaram a esse resultado; os testes de Piaget que mostram isso constituem uma excelente refutação da fórmula de Alain: Saber, é saber que se sabe" (SARTRE, 2010a, p. 19).
} 
consciência não posicional de si, ou consciência (de) si, determina-se como consciência de percepção e como percepção. O (de), aqui, responde a um signo tipográfico com vistas a marcar uma diferença em relação ao conhecimento, porquanto “(...) o 'de si' desperta ainda a ideia de conhecimento” (SARTRE, 2010a, p. 20). A percepção é consciência não posicional de percepção, daí que a estrutura do ser-para-si designe, em primeiro lugar, esta característica não-tética da consciência.

En passant, a consciência (de) $\mathrm{si}^{{ }^{12}}$ é, como aludimos, relação imediata e não cognitiva de si a si: ela é, antes de ser um conhecimento, uma consciência de ponta a ponta, uma consciência (de) si - não-tética, não-reflexiva, não-posicional - consciente do objeto. Como, afinal, minha consciência perceptiva do $\mathrm{X}$ transcendente pode estar voltada para este $\mathrm{X}$ e, ao mesmo tempo, ser consciência (de) si mesma? Em outros termos, como pode ser consciência (de) si mesma- consciência irrefletida - sem se colocar, ela mesma, como objeto? Este arranjo ontofenomenológico, nas tramas da presente obra, só se esclarece se este "si mesma" não fizer remissão senão a nada: este itinerário sinaliza uma "dupla necessidade em virtude da qual ela não pode nem ausentar-se dela mesma e nem afastarse dela mesma, mas somente se faltar" (NARBOUX, 2015, p. 74), ou seja, ser falta em relação ao ser, (falta de ser, descompressão de ser) e, igualmente, não coincidência consigo mesma. Entrementes, graças à ideia fundamental de uma consciência pré-reflexiva (ser transfenomenal da consciência), $E N$ desconstrói a primazia do conhecimento que toma a reflexão - ou consciência de segundo grau - como o fundamento par excellence do cogito.

Esta relação a si da consciência pré-reflexiva, uma vez estabelecida, exclui toda forma de conhecimento de si porque permanece nas dependências de sua relação intencional com o X transcendente. Ao mesmo tempo, uma vez instituída esta consciência de primeiro grau, a ontologia fenomenológica é capaz de assegurar a relação inexorável da consciência com o mundo sem, todavia, chafurdar-se no esse est percipi. A consciência (de) si, mormente, é tão somente consciência do objeto transcendente e, através deste objeto, consciência não posicional (de) si. O ser da consciência não é redutível ao conhecimento à medida que este ser

\footnotetext{
${ }^{12}$ Deve-se atentar para o fato de que: "Esta consciência (de) si, não devemos considerá-la como uma nova consciência, mas como o único modo de existência que seja possível para uma consciência de qualquer coisa" (SARTRE, 2010a, p. 20).
} 
é a própria consciência (de) si e a condição mesma do conhecimento: "saber é ter consciência de saber"; ou seja, o ser transfenomenal da consciência, sua pré-reflexividade, é ontologicamente anterior ao conhecimento, e sinaliza, desta lida, a irrupção da existência. Antes de ser conhecimento, a consciência "é um pleno (absoluto) de existência e esta determinação de si por si é uma característica essencial” (SARTRE, 2010a, p. 22). N'outras palavras, na medida em que o pleno (absoluto) é definido pelo primado da existência sob a essência, convém afirmar que a existência da consciência precede sua essência.

\section{II - O ser-em-si}

Operada a distinção ser e fenômeno, o filósofo indicará, através de uma "prova ontológica", que a transfenomenalidade do ser da consciência exige eo ipso a transfenomenalidade do ser do fenômeno: sumariamente, esta prova ontológica provém do ser do cogito pré-reflexivo, consciência de primeiro grau. Preservando a descoberta essencial de Husserl contra ele mesmo - a intencionalidade /transcendência - ${ }^{13}$, deve-se sublinhar que a consciência, enquanto consciência do X qualquer, tem a transcendência como sua estrutura constitutiva: isso quer dizer, finalmente, que a "consciência nasce tendo por objeto um ser que ela não é. É o que nós chamamos a prova ontológica” (SARTRE, 2010a, p. 28). Outrossim, a intencionalidade reafirma a prova ontológica ao instituir o movimento da consciência em direção a um objeto que ela não é; afirmar que toda consciência é consciência de algo significa afirmar que "não há ser para a consciência fora desta obrigação precisa de ser intuição reveladora de alguma coisa, ou seja, de um ser transcendente" (SARTRE, 2010a, p. 28): a imanência somente pode definir-se quando da apreensão de algo transcendente.

\footnotetext{
${ }^{13}$ De acordo com $E N$, Husserl será acusado de "ter pensado a intencionalidade como relação de pura presença ao objeto singular" (DE COOREBYTER, 200o, p. 167). Tal censura é expressa da seguinte forma por Sartre (201ob, pp. 144-145): "Husserl foi, ao longo de toda a sua carreira filosófica, obcecado pela ideia da transcendência e ultrapassamento. Mas os instrumentos filosóficos de que dispunha, em particular sua concepção idealista de existência, privaram-no dos meios para dar conta desta transcendência: sua intencionalidade não é senão a caricatura disso. A consciência husserliana, na verdade, não pode se transcender nem para o mundo, nem para o futuro e nem para o passado".
} 
Nos quadros da obra em tela, a intuição será definida como a presença da consciência à coisa ${ }^{14}$. Aqui, todavia, imanência \& transcendência são salvaguardadas em seu ser graças à descoberta do ser transfenomenal da consciência e do ser transfenomenal do fenômeno. Ora, se já não é mais possível tornar fenomenal este ser que se revelou transfenomenal, a ontologia fenomenológica sartreana, perseverando a diferença entre ser e fenômeno, irá conduzir-nos a uma nova dualidade (ou oposição), qual seja: a do l'être-en-soi e do l'être-pour-soi (responsável pela fenomenização), pour-soi "que, se não suporta o ser, suporta todo o processo de fenomenização” (MOUTINHO, 2006, p. 93). Porém, antes de mergulharmos na tessitura do ser-para-si, faz-se imperativo que explicitemos o sentido do ser ao qual este se opõe, qual seja, o ser-em-si; vejamo-lo.

Começaremos notando que este ser (o ser-em-si) possui três aspectos: "O ser é. O ser é em si. O ser é o que é" (SARTRE, 2010a, p. 33) Idêntico a si mesmo, o ser-em-si é sem razão de ser, sem necessidade alguma, inteiramente contingente. Em oposição à imanência da consciência, imanência definida como uma relação a si, o em-si pode ser compreendido como uma espécie de imanência que não poderia se realizar à medida que ele é pleno de si mesmo; daí a assertiva segundo a qual este ser é, doravante, em si: l'être est en soi. Se indicamos que este ser é em si, é necessário sublinhar que este si não opera uma remissão a si tal como ocorre na consciência (de) si, pois este si do ser é uma plena identidade, logo, o ser-em-si está todo ele preenchido por si mesmo, ele é opaco a si mesmo: o ser é o que é (l'être est ce qu'il est) ${ }^{16}$ ao contrário do para-si que, como veremos, não é o que é e é o que não é. Maciço ${ }^{17}$, o em-si é tido como uma plena positividade que não pode comportar a mínima fissura de negação ${ }^{18}$, o que quer dizer que "ele não poderia não ser o que ele não é". Na medida em que ele jamais se coloca senão como idêntico a si, não existe

\footnotetext{
${ }^{14}$ Veremos, no decorrer de nossas investigações, que esta intuição, isto é, a presença da consciência à coisa é dada a partir de uma díade indicada pelo filósofo como reflexo-refletidora.

${ }^{15}$ Ainda: "o ser é, sem razão, sem causa e sem necessidade; a definição própria ao ser entrega-nos sua contingência original” (SARTRE, 2010a, p. 667).

${ }^{16}$ Ser o que é, de acordo com Sartre (2010, p. 32), “é um princípio contingente do ser em si”. Aliás, enquanto opaco, ele será o avesso da pura translucidez da consciência.

17 “O ser-em-si não tem segredo: ele é maciço" (SARTRE, 2010a, p. 32).

18 “(...) observar-se que o ser-em-si é plena positividade e não contém nele nenhuma negação” (SARTRE, 2010a, p. 40).
} 
alteridade que o atravesse: "ele é, e, quando se desmorona, sequer podemos dizer que não é mais. (...) ele mesmo não existe como se fosse algo que falta ali onde antes era: a plena positividade do ser se restaurou sobre seu desmoronamento" (SARTRE, 2010a, p. 33).

Sendo plena positividade maciça e idêntica a si mesmo, forço é admitir que o ser-em-si é, e, dada uma tal característica, ele não poderia jamais ser derivado do nada, nem de outro ser, nem do possível e nem mesmo de uma lei necessária: este ser é, é o que é, é em si. Diremos, à guisa destes três enunciados acerca do em-si, que sua transcendência é transfenomenal, ou seja, "não tem necessidade, senão de si mesmo para ser, ele não remete senão a si mesmo” (SARTRE, 2010a, p. 207).

\section{III - O cogito e sua estrutura reflexo-refletidora}

Na esteira das considerações tecidas acima, compreenderemos a assertiva sartreana segundo a qual o conhecimento deve ser buscado no ser-para-si. Contudo, antes de passarmos efetivamente a este assunto, precisemos o sentido ontofenomenológico do cogito: tratar-se-á, neste momento, de analisá-lo a partir de sua pré-reflexividade, ou seja, sua relação a si (imanência) e, neste mesmo itinerário, de seu transcender para fora de si, movimento de transcendência operado graças à ideia fundamental de intencionalidade (transcendência): duplo movimento pelo qual apreendemos a presença a si da consciência como abertura ao mundo e a abertura ao mundo como presença a $\mathrm{si}^{19}$. Nesta toada, devemos lembrar, tal como havia postulado a "Introdução" de $E N$, que o ser da consciência está em questão para ela, ou seja, seu ser é menos uma coincidência do que uma presença a si; não há adequação plena de seu ser consigo mesma, adequação que, por definição, pertencerá somente ao serem-si, ser que é o que é, plenitude maciça de identidade. Não possuindo uma fissura, mesmo que mínima, pela qual a dualidade poderia deslizar, o em-si é uma pura densidade infinita; daí sua plena identidade, sua total adequação entre conteúdo e continente: "não há o menor vazio no ser, a menor fissura pela qual o nada poderia deslizar” (SARTRE, 2010a, p. 110). Mas a consciência, ao contrário desta total plenitude identitária, opaca e maciça, é uma descompressão de ser, entrementes, não traz em seu ser a

\footnotetext{
${ }^{19}$ Este exame será realizado na segunda parte, capítulo primeiro, seção I, “La présence à soi”, de $E N$.
} 
plena identidade: se, por exemplo, creio, não posso dizer que esta crença seja o que é no sentido identitário $\mathrm{A}=\mathrm{A}$, mas, antes, que ela é consciência (de) crença.

Ora, pelo simples fato de que a crença é apreendida como consciência (de) crença, ela já não é mais crença como, por exemplo, a mesa é somente a mesa, ela é "crença perturbada". Postular que minha crença é consciência (de) crença é produzir um juízo ontológico ao invés de um juízo de identidade: "o sujeito e o atributo são radicalmente diferentes, embora na unidade indissolúvel de um mesmo ser" (SARTRE, 2010a, p. 111); a crença, tal como a consciência, não é o que é e é o que não é; em nenhuma hipótese, portanto, podemos dizer que a crença é crença ou que a consciência é consciência. Há aqui, como salienta o filósofo, um duplo jogo de remissão, qual seja, a consciência (de) crença é crença e a crença é consciência (de) crença; cada um dos termos remete, necessariamente, ao outro, e são, ao mesmo tempo, diferentes um do outro. Não devemos erigir a crença apenas como objeto de visada intencional, pois "a crença se tornaria pura qualificação transcendente e noemática da consciência; a consciência teria a liberdade de determinarse como quisesse em relação a essa crença (...)" (SARTRE, 2010a, p. 111). A consciência (de) crença, ainda que altere a crença, não se distingue dela, mas existe para realizar o ato de fé: por conseguinte, consciência (de) crença \& crença são um único e mesmo ser cuja característica é o da imanência absoluta. Todavia,

(...) se quisermos apreender este ser, ele desliza entre os dedos e nos encontramos frente a um esboço de dualidade, de um jogo de reflexos, pois a consciência é reflexo (reflet); mas, justamente enquanto reflexo, ela é a refletidora (réfléchissant) e, se tentamos captá-la como refletidora, ela se desvanece e recaímos no reflexo. Esta estrutura do reflexo-refletidor (...), caso nós a aceitemos como se dá, obriga-nos, ao contrário, a conceber um modo de ser diferente do em-si: não uma unidade que contenha a dualidade, nem uma síntese que ultrapasse e capte os momentos abstratos da tese e da antítese, mas uma dualidade na unidade, um reflexo que é sua própria reflexão (SARTRE, 2010a, p. 112).

O jogo reflexo-refletidor deve ser concebido, ao contrário de uma operação reflexiva que faria com que a consciência fosse consciência posicional de si, como um fenômeno de remissão (consciência (de) crença \& crença) próprio à pré-reflexividade da consciência; ao ser consciência 
(de) crença, a consciência é, nesta mesma atividade, consciência (de) si: "o reflexo é, ele mesmo, o refletidor, e o refletidor, o reflexo” (SARTRE, 2003, p. 155). Esta "dualidade na unidade", indicada pelo jogo reflexo-refletidor, aponta para a necessária sobreposição do intencional ao pré-reflexivo: ora, sem a consciência (de) crença (intencionalidade), a consciência (de) si (pré-reflexividade) se extinguiria e, por outro lado, sem a consciência (de) si, a consciência (de) crença permaneceria puramente inconsciente. Assim, a remissão perpétua do reflexo ao refletidor e do refletidor ao reflexo sinaliza, fundamentalmente, a dinâmica ontofenomenológica de uma consciência que, por ser nada de ser, descompressão de ser, não identidade a si, deve estar voltado ao X qualquer (aqui, no caso, a crença). O si (da consciência (de) si), por óbvio, não poderá jamais ser uma propriedade ontológica do ser-em-si (caso lhe pertencesse, este deixaria de possuir sua plena e total identidade): entrementes, "o si remete, mas remente precisamente ao sujeito" (SARTRE, 2010a, p. 112).

Talvez, o ponto o mais paradoxal da consciência (de) si seja devido ao fato de que o sujeito é e não é si: não pode ser si (tal como $\mathrm{A}=\mathrm{A}$ ), pois tal coincidência consigo faria desaparecer o si, mas, igualmente, não pode não ser o si, já que este é a indicação do próprio sujeito. Frisemos: a consciência (de) si designa uma presença a si sob o modo da não identidade a si: a consciência, visando o X qualquer, jamais poderá coincidir consigo mesma sob a forma de uma pura e plena identidade a si. Ora, talvez este si que o sujeito não deva e deva ser não seja assim tão paradoxal se nos lembrarmos de que a consciência não é o que é e é o que não e, sobretudo, se nos detivermos no fato de que, como aludimos, o si sinaliza menos uma coincidência do que uma presença: "o si representa, por conseguinte, uma distância ideal na imanência entre o sujeito e si mesmo, uma maneira de não ser sua própria coincidência, de escapar à identidade colocando-a como unidade" (SARTRE, 2010a, p. 113). Se se tratasse de uma coincidência (de uma identidade), fatidicamente, o parasi deixaria de ser consciência intencional - movimento de transcendência - para, então, tornar-se um ser inerte à maneira do em-si; n'outras palavras, a não coincidência do si é aqui uma condição capital para que a consciência seja consciência (de) si na exata medida em que ela é consciência (de)...! Forçosamente, "o sujeito não pode ser si mesmo. Ele é para si mesmo. Ele não pode mais não ser si mesmo” (SARTRE, 2003, p. 
156). Daí que a lei ontofenomenológica do para-si consista, precisamente, em ser si mesmo sob a forma da presença a si (e não da coincidência a si).

A presença é constituída, ao contrário da total identificação a si do ser-em-si, a partir de uma fissura ontológica própria ao ser-para-si, isto é, a partir de seu nada de ser, afinal, "se ele é presente a si, é porque ele não é inteiramente si”, e, por conseguinte, "a presença é uma degradação imediata da coincidência, pois ela supõe a separação" (SARTRE, 2010a, p. 113). O indivíduo, presente a si mesmo, está separado de si por nada (rien): nada pode separar a consciência (de) crença da crença, mas a consciência é e não é essa crença, assim como a crença é não é consciência (de) crença; a crença não pode ser senão consciência (de) crença (o que significa, n'outras palavras, que ela não pode ser crença idêntica a si, uma crença em-si). Sob uma tal ótica, diremos que o para-si é um ser para o qual, em seu próprio ser, está em questão o seu ser enquanto este ser é um certo modo de não ser um ser que ele põe como o outro dele, o outro que não si mesmo. Sartre novamente:

\footnotetext{
A separação que separa a crença dela mesma não se deixa nem apreender e nem mesmo ser concebida à parte. Se tentamos descobri-la, desvanece: encontramos a crença como pura imanência. Mas se, ao contrário, queremos apreender a crença enquanto tal, acha-se aí a fissura, aparecendo quando não queremos vê-la, e desaparecendo quando buscamos contemplá-la. (...) a fissura infraconsciente (intraconscientielle) é um nada (rien) fora daquilo que nega, e somente pode ser na medida em que não a vemos. Esse negativo que é nada de ser e conjuntamente poder nadificador é o nada. Em nenhum outro lugar poderíamos apreendê-lo em uma tal pureza (SARTRE, 2010a, p. 114).
}

Esse nada em estado de pureza, proveniente da consciência préreflexiva, é a prova cabal de que a consciência de... não pode existir separada da consciência (de) si, isto é, anuncia a dupla impossibilidade da consciência em não se refletir sem, por outro lado, ser o refletidor: "a consciência é reflexo com a condição de ser também refletidor, consciência (de) si do reflexo (...)" (DE COOREBYTER, 2005, pp. 92-93). Nesta dupla dimensão - consciência (de) si e consciência intencional de..., observamos que se a intencionalidade designa o movimento de transcendência da consciência para fora de si mesma, tal movimento implica, forçosamente, uma dimensão interior pela qual a consciência, sendo consciência de... é 
consciência (de) $\mathrm{si}^{20}$. E porque presença a si, remissão do reflexo ao refletidor e do refletidor ao reflexo (consciência (de) si à consciência de... e vice-versa), a consciência vive seu si à distância, n'outras palavras, está impedida, como já indicamos, de coincidir consigo: ora, uma tal distâncianão coincidente é tributária do jogo reflexo-refletidor exatamente porque, ao contrário de um espelho que reflete a mesa e permanece, como a mesa refletida, inconsciente, a consciência, para refletir o Outro dela (consciência de...), deve apreender a si mesma como não sendo esse Outro (consciência (de) si), logo, deve negar para poder afirmar. Daí que o que separe a consciência (de) crença da crença seja, precisamente, o Nada: “(...) para que exista um si, é preciso que a unidade deste ser comporte seu próprio nada como nadificação do idêntico. Pois o nada que desliza na crença é seu nada, o nada da crença como crença em si” (SARTRE, 2010a, p. 114). Assim, diremos que o para-si é fundamento de seu nada sob a forma da díade reflexo-refletidor (ademais, pela estrutura reflexorefletidor, observaremos que o para-si se faz ser sua própria falta de ser).

Ora, para que a consciência seja consciência (de) si, ela deve, necessariamente, realizar um movimento intencional de transcendência em direção ao X qualquer, movimento que, por sua vez, faz com que ela exista à distância de si; o para-si está fadado à obrigação ontofenomenológica de "não existir senão como um alhures em relação a si mesmo, de existir como um ser que se afeta perpetuamente de uma inconstância de ser" (SARTRE, 2010a, p. 114). Porque nadificação do ser, nada de ser em relação ao ser-em-si, o para-si busca, na transcendência, seu preenchimento de ser e, neste movimento mesmo de transcendência, sua imanência, antes de ser conhecida, é existida sob a forma de consciência (de) si. O cogito pré-reflexivo é o ato pelo qual o sujeito mantem uma relação com o mundo e, ao mesmo tempo, uma relação (não idêntica) a si: "(...) é da natureza mesma da consciência existir em círculo" (SARTRE, 2010a, p. 20). Ainda, esta descrição da démarche do cogito préreflexivo acentua a prova ontológica: pela descompressão de ser, uma negatividade é instalada e a identidade a si do ser-em-si é fissurada pelo surgimento de uma consciência que se faz relação ao em-si e, nesse mesmo ato ontológico, negação dele. Por este ato ontológico (relação \& negação ao

\footnotetext{
${ }^{20}$ N'outros termos, este fato ontofenomenológico poderia ser designado da seguinte maneira: toda consciência é consciência (de) si na exata medida em que é consciência do X qualquer. Doravante, a consciência do X vem acompanhada de uma consciência (de) si.
} 
em-si), o para-si se faz presença a si. Daí que, degradando-se em presença a si, o nada (e somente ele), poderá ser a possibilidade do ser: na medida em que o em-si está isolado em seu ser por uma plena positividade de identificação, nenhum ser pode chegar ao ser pelo ser, a não ser se esse ser for um nada de ser, mas este nada, "sendo nada de ser, só pode vir ao ser pelo próprio ser. Sem dúvida, vem ao ser por um ser singular, que é a realidade-humana" (SARTRE, 2010a, p. 115).

Reforcemos a tinta: se o para-si é uma desintegração do em-si, isso significa que o para-si não é o Outro do em-si, seu exato oposto, mas, ao contrário, "o para-si é o em-si ele mesmo que se faz outro que si em seu cerne, que se afeta de nada em seu coração, 'como um verme', por um gesto inexplicável e contingente que Sartre chama de ato ontológico” (DE COOREBYTER, 2012, p. 8). Doravante, pela análise da consciência (de) si, somos conduzidos à presença a si.

\section{IV - O fundamento ontofenomenológico do conhecimento}

Depois de realizada esta incursão pelos momentos chave de $E N$, podemos, finalmente, analisar a questão do conhecimento tal como esta se apresenta no capítulo três da segunda parte. Em primeiro lugar, o filósofo começa afirmando que somente há conhecimento intuitivo pelo fato de que a dedução e o discurso, impropriamente chamados de conhecimento, não são senão instrumentos que conduzem à intuição. Se, portanto, "nós nos perguntamos o que é a intuição, Husserl responderá, em acordo com a maioria dos filósofos, que ela é a presença da 'coisa' (Sache) em pessoa à consciência” (SARTRE, 2010a, p. 209). O conhecimento é um tipo de ser definido enquanto presença a... Todavia, como vimos ao longo deste artigo, o em-si, enquanto plena identidade maciça, não poderia jamais ser presença, pois, sob a égide desta identidade, ele não remete senão a si mesmo. Neste sentido, o ser-presente deve ser buscado a partir do serpara-si; disso a assertiva sartreana: "a intuição é a presença da consciência à coisa” (SARTRE, 2010a, p. 209). Ora, deve-se buscar o ser-presente a partir do modo de ser ek-stático da consciência porque, como vimos, ela somente poderá ser consciência (de) si na exata medida em que for, igualmente, consciência de objeto: "com efeito, é através disso que ela é consciência, que ela se distingue a seus próprios olhos e que ela pode ser 
consciência (de) si” (SARTRE, 2010a, p. 209). Mas o que significa esta necessidade, para a consciência, de ser consciência de alguma coisa?

Ora, esta necessidade deve ser buscada a partir da díade reflexorefletidora: se o reflexo e o refletidor remetem, necessariamente, um ao outro, isso significa que a consciência não poderia ser consciência do $\mathrm{X}$ qualquer sem, por outro lado, ser consciência (de) si. Porém, "se o refletidor não é senão o refletidor deste reflexo, e se o reflexo não pode ser caracterizado senão por seu 'ser para se refletir neste refletidor', os dois termos da quase-díade, apoiando um contra o outro seus dois nadas, aniquilam-se conjuntamente" (SARTRE, 2010a, p. 209). Para que isso não ocorra, é necessário, como frisa Sartre, que o refletidor reflita alguma; contudo, se o reflexo fosse este alguma coisa, independente de seu serpara-se-refletir, seria necessário que ele fosse, ao invés de reflexo, qualificado como em-si: "isso seria introduzir a opacidade no sistema 'reflexo-refletidor' e, sobretudo, realizar a cissiparidade esboçada, pois no para-si o reflexo é também o refletidor" (SARTRE, 2010a, p. 209). Por outro lado, se o reflexo fosse qualificado (isto é, fosse em-si), ele se separaria do refletidor e o cogito, portanto, tornar-se-ia impossível.

Se quisermos sair desta aparente aporia, será necessário que o reflexo se faça qualificar por outra coisa que ele, n'outros termos, que ele se reflita enquanto relação a um fora que ele não é: “o que define o reflexo para o refletidor, é sempre isso ao qual ele é presença. Mesmo uma alegria, apreendida no plano do irrefletido, não é senão a presença 'refletida' de um mundo sorridente e aberto (...)” (SARTRE, 2010a, p. 210). N'outras palavras, trata-se de mostrar que a consciência será consciência do objeto enquanto ela, neste mesmo ato, apreender a si mesma (irrefletidamente) como não sendo este objeto: "a presença envolve uma negação radical como presença ao que não somos. Está presente a mim o que não é eu” (SARTRE, 2010a, p. 210). Ademais, seria impossível construir qualquer noção de objeto se, originalmente, o conhecimento não fosse uma relação negativa, quer dizer, se o objeto não fosse designado negativamente como isto que não é a consciência: o objeto é, antes de toda comparação, antes de toda construção, "o que está presente à consciência como não sendo a consciência. A relação original de presença, como fundamento do conhecimento, é negativa" (SARTRE, 2010a, p. 210). Sobremaneira, se o ser-em-si é uma plenitude de identidade, forço será admitir que ele não poderá exprimir esta negação. 
Doravante, é somente a partir de um ser que é, em seu ser, nada de ser, que a negação irrompe no mundo; e se o para-si é um ser no qual seu ser está em questão, completaremos esta característica ontofenomenológica asseverando que este ser é essencialmente uma certa maneira de não ser um ser que ele põe. O conhecimento, portanto, aparece como um modo de ser do para-si: "o conhecer não é nem uma relação estabelecida entre dois seres, nem uma atividade de um desses dois seres, nem uma qualidade, propriedade ou virtude. Mas é o ser mesmo do parasi enquanto ele é presença a...", isto é, “enquanto ele tem de ser o seu ser ao se fazer não ser um certo ser ao qual ele está presente" (SARTRE, 2010a, p. 210). Conclusão desta assertiva: o para-si somente pode ser sob o modo de um reflexo ao se fazer refletir como não sendo o ser, o que significa que a consciência somente é consciência do X qualquer enquanto, neste mesmo ato, ela não é este $X$ qualquer que ela apreende. E este X qualquer que deve qualificar o refletido é, por conseguinte, negação pura: "o refletido se faz qualificar de fora, ao lado de um certo ser como não sendo este ser, e isso é precisamente o que chamamos "ser consciência de alguma coisa"” (SARTRE, 2010a, p. 211).

Esta negação pura ou negação original diz respeito a um tipo de negação interna que é diferente de uma negação externa. Esta segunda negação aparece como um elo de pura exterioridade estabelecido por um observador externo: se, por exemplo, afirmo que a mesa não é o computador, é preciso convir que o fundamento desta negação não advém de nenhum desses dois objetos, ambos são o que são, isto é, são em-si. Esta negação externa, portanto, sinaliza um tipo de ligação categorial que eu estabeleço entre os dois objetos sem que ele sejam afetados em seu ser por ela; não esta no ser da mesa não ser o computador assim como não está no ser do computador não ser a mesa. Tal assertiva, no entanto, modificase completamente quando passamos para a negação interna: esta será definida, ao contrário da negação externa, como uma relação entre dois seres onde aquele é negado é, igualmente, qualificado; neste escopo, esta negação é "uma ligação de ser essencial" oriunda do para-si, pois "somente o para-si pode ser determinado em seu ser por um ser que ele não é” (SARTRE, 2010a, p. 211). Desta assertiva, chegamos ao fulcro do conhecimento: este somente poderá irromper no mundo a partir de um ser que é presente ao X qualquer enquanto não sendo este $\mathrm{X}$ qualquer; "a relação fundamental pela qual o para-si tem de ser como não sendo este 
ser particular ao qual ele está presente é o fundamento de todo conhecimento deste ser" (SARTRE, 2010a, p. 212).

O para-si, via negação interna, apreende o objeto e, nesta apreensão, apreende a si mesmo como não sendo este objeto; trata-se, portanto, de uma nadificação do próprio para-si para que o objeto seja apreendido: "na negação interna, o para si é esmagado por aquilo que ele nega. As qualidades negadas são precisamente o que há de mais presente no para-si", afinal, "é a partir delas que ele retira a sua força negativa e que ele a renova perpetuamente” (SARTRE 2010a, p. 212) ${ }^{21}$. A passagem pode ser simplificada por nós da seguinte forma: a consciência, para ser consciência de si, precisa ser consciência das qualidades do objeto qualquer, sem, no entanto, ser essas qualidades; em outras palavras, ela é consciência das qualidades estando consciente (irrefletidamente) de não sê-las; ela é consciência das qualidades na exata medida em que, enquanto consciência, ela não é essas qualidades. Logo, observar-se que a nadificação da consciência apenas se realiza a partir de seu contato com o ser-em-si: "o para-si está fora de si no em-si porque se faz definir através do que ele não é; a ligação primeira do em-si ao para-si é, portanto, uma ligação de ser" (SARTRE, 2010a, p. 213). Destarte, no plano do conhecimento, esta ligação primeira deverá ser compreendida como uma "ligação de ser ontológica" através da qual o para-si se determina na existência a partir do em-si; isto significa que o X qualquer é condição sine qua non para que a consciência se apreenda a si mesma como consciência (de) si.

A partir do que dissemos nos parágrafos acima, será preciso sublinhar que no conhecer apenas encontraremos o conhecido (o objeto apreendido pela consciência sob o modo da negação interna enquanto presença da consciência ao X qualquer), pois o cognoscente, por sua vez, não é apreensível à medida que se nega/nadifica para que o objeto seja apreendido: o cognoscente somente faz com que haja um ser-aí do conhecido, uma presença. Daí que a nadificação, antes de figurar como uma mera consequência pessimista do chamado "existencialismo sartreano” ${ }^{22}$, seja, de fato, um mecanismo fundamental para que se

\footnotetext{
${ }^{21}$ Portanto: "Chamaremos de transcendência esta negação interna e realizante que desvela o em-si ao determinar o para-si em seu ser” (SARTRE, 2010a, p. 216).

${ }^{22}$ É comum ouvir, por leitores despercebidos de Sartre, que o Nada advém como um conceito pessimista desta filosofia. Ao contrário desta assertiva, o nada é justamente aquilo que permite ao para-si agir (viver) no mundo, ou
} 
estabeleça a relação da consciência com o mundo sem, no entanto, esbarrarmos no idealismo ou no realismo (disso, por exemplo, a prerrogativa sartreana de que o para-si se perde na nadificação para fazer com que um mundo exista ${ }^{23}$ ). En résumé, para que haja apreensão do $\mathrm{X}$ qualquer, faz-se imperativo que a consciência seja descompressão de ser, nada de ser.

Das considerações tecidas acima, podemos alargar o sentido da prova ontológica: seu sentido fundamental sinaliza a dependência absoluta de um nada de ser em relação ao ser transcendente do qual ele será o nada; a prova ontológica "sinaliza que o alvo da visada (o X transcendente) é necessariamente uma pura plenitude de ser, e que a fonte (a consciência) é necessariamente um puro vazio de ser" (NARBOUX, 2015, p. 76) ${ }^{24}$, um nada de ser, fecho de ouro da correlação entre o visado e o apreendido, o cognoscente e o conhecido. Se o para-si se perde na nadificação para que um munda advenha, vejamos que este advir não significa, no caso do conhecimento, uma qualquer modificação do para-si ao em-si pelo fato de que na relação cognoscente-conhecido, o cognoscente não é senão aquilo pelo qual "há" o ser: "isto basta para afirmar que o fenômeno original de conhecimento não acrescenta nada ao ser e não cria nada. Nele, o ser não é enriquecido, pois o conhecimento é negatividade pura" (SARTRE, 2010a, p. 215).

Ademais, se o conhecimento é negatividade apura, a relação interna do conhecer e do ser poderia ser compreendida a partir do termo realizar com o seu duplo sentido ontológico e gnosiológico: é fazer com que haja o ser (isto é, que ele seja apreendido) enquanto a consciência tem de ser a negação refletida deste ser. Um exemplo: o desvelamento da espacialidade, pelo para-si, não é senão o desvelamento (irrefletido) do para-si como inextenso, "é através da extensão do em-si transcendente que o para-si se faz anunciar e realiza a sua própria inextensão (inextention)” (SARTRE, 2010a, p. 215). Nesta perspectiva, o "real é realização" porquanto a negatividade, como transcendência original e fundamento do

\footnotetext{
seja, operar seu movimento de transcendência em direção ao ser: "se o homem se comporta face ao em-si - e nossa interrogação filosófica é um tipo desse comportamento -, é porque ele não é esse ser. Encontramos, portanto, o nãoser como condição da transcendência em direção ao ser" (SARTRE, 2010a, p. 79).

23 “(...) nosso surgimento é uma paixão, nesse sentindo de que nos perdemos na nadificação para que um mundo exista” (SARTRE, 2010a, p. 505).

${ }^{24}$ Notemos: vazio de ser no sentido de nada de ser.
} 
conhecimento, faça com que um objeto qualquer (enquanto fenômeno) exista e, neste mesmo ato, faça com que a consciência apreenda a si própria (irrefletidamente): toda consciência só será consciência (de) si na exata medida em que for consciência do objeto transcendente. Enfim, "se o sentido do para-si esta fora de si, no ser, é pelo para-si que o sentido do ser aparece” (SARTRE, 2010a, p. 217).

\section{V - Conclusão}

Resumo da ópera: o conhecimento, como tentamos demonstrar aqui, é relação original de presença da consciência ao objeto, é apreensão deste objeto pela consciência como não sendo a consciência. Sartre conceberá que o ser do para-si é conhecimento do ser, mas acrescentado que há um ser deste conhecimento. Isto posto, observou-se que a identidade do ser do para-si e do conhecimento, antes de sinalizar que o conhecimento é a medida do ser, é tributária de um para-si que, enquanto nada de ser, anuncia a si mesmo a partir do em-si, afinal, como não deixamos de nota, só há consciência se houver, necessariamente, consciência de objeto. Nesta perspectiva ontofenomenológica, "o conhecimento não é senão a presença do ser ao para-si e o para-si não é senão o nada (rien) que realiza esta presença" e, segue Sartre, "o conhecimento é, por natureza, ser ek-stático que se confunde com o ser ek-stático do para-si” (SARTRE, 2010a, p. 253). Finalmente, o conhecimento é expressão ontofenomenológica do surgimento absoluto do para-si no meio do ser e para além do ser enquanto negação deste ser e nadificação de si. Isto significa que o conhecimento não poderá mais ser visado como um mero atributo, acidente ou função do ser: ele sinaliza, antes, a relação do ser-para-si ao ser-em-si como relação ontológica fundamental.

\section{Referências}

CABESTAN, Philippe. L'être et la conscience: Recherches sur la psychologie et l'ontophénoménologie sartriennes. Paris: Éditions OUSIA, 2004.

DE COOREBYTER, Vincent. Sartre face à la phénoménologie: Autour de "L'intentionnalité" et “La transcendance de L'ego". Paris: Éditions OUSIA, 2000. 
. “Les paradoxes du désir dans L’être et le néant”; in: Sartre. Désir et liberté. Paris: PUF, 2005, pp. 85-112.

. "L'être et le néant ou le roman de la matière"; in: Les Temps Modernes: lecteurs de Sartre, $n^{\circ}$ 667. Paris: Éditions Gallimard, 2012, pp. 1-11.

MOUILLE, Jean-Marc. Sartre: Conscience, ego et psyche. Paris: PUF, 2000.

MOUTINHO, Luiz Damon Santos. "O dualismo fundamental da fenomenologia sartriana”; in: Questões de Filosofia Contemporânea. São Paulo: Discurso Editorial, 2006, pp. 89-95.

NARBOUX, Jean-Philippe. “Intentionnalité et négation dans L'être et le néant; in: Sartre. L'être et le néant. Nouvelles lectures. Textes réunis par Jean-Marc Mouille et JeanPhilippe Narboux. Paris: Les Belles Lettres, 2015, pp. 57-92.

RODRIGUES, Malcom Guimarães. Consciência e má-fé no jovem Sartre. A trajetória dos conceitos. São Paulo: ed. UNESP, 2010.

SARTRE, Jean-Paul. La transcendance de l'ego et autres textes phénoménologiques. Texte introduits et annotés par V. de Coorebyter, Paris: J. Vrin, 2003.

. L'être et le néant - Essai d'ontologie phénoménologique. Paris: Éditions Gallimard, “Tel”, 2010a.

. "Carnets de la drôle de Guerre"; in: Les mots et autres écrits autobiographiques. Paris: Gallimard, "Bibliothèque de la Pléiade”, 2010b.

. Qu'est-ce que la littérature?. Paris: Éditions Gallimard, “Idées”, 1980.

SOUZA, Thana Mara de. Tensão e ambiguidade na filosofia de Jean-Paul Sartre”; in: Revista Trans/Form/Ação, v. 35, n.1. Marília: UNESP, 2012, pp. 147-166. 